\title{
Levantamento das espécies de Amasonia (Lamiaceae) para o Brasil ${ }^{1}$
}

\author{
Survey of Amasonia (Lamiaceae) species to Brazil
}

Juliana Silva dos Santos ${ }^{2,5}$, Flávio França ${ }^{3}$, Marcos José da Silva ${ }^{4}$ \& Margareth Ferreira de Sales ${ }^{2}$

\begin{abstract}
Resumo
O presente trabalho consiste no levantamento das espécies de Amasonia L.f. para o Brasil, com base em observações de campo e estudo de espécimes de herbários, além de fotografias de tipos e de documentação bibliográfica. Amasonia é um gênero neotropical, com distribuição na América do Sul e Antilhas. Oito espécies são reconhecidas para o gênero (A. angustifolia, A. arborea, A. calycina, A. campestris, A. hirta, A. lasiocaulos, $A$. obovata e $A$. spruceana) ocorrendo principalmente nas regiões amazônica e centro-oeste do país. Chave para a identificação, ilustrações e dados de floração e frutificação são fornecidos.

Palavras-chave: Verbenaceae, Ajugoideae, taxonomia, flora do Brasil.
\end{abstract}

\begin{abstract}
This paper, a survey of Amasonia L.f. from Brazil, was based on field observations and study of herbarium specimens, photographs of the types, besides bibliographic documentation. Amasonia is a neotropical genus, distributed in South America and Antilles. Eight species are recognized here in the genus (A. angustifolia, A. arborea, A. calycina, A. campestris, A. hirta, A. lasiocaulos, A. obovata and A. spruceana) distributed mainly in the Amazon and central-western country. A key to identify the species, illustrations and flowering and fructification periods are provided.
\end{abstract}

Key words: Verbenaceae, Ajugoideae, taxonomy, flora of Brazil.

\section{Introdução}

Amasonia L.f. compreende oito espécies predominantes da porção norte da América do Sul, em especial nos escudos das Guianas e do Brasil (Steane et al. 2004; Harley et al. 2004). Em território brasileiro, o gênero distribui-se especialmente nas Regiões Centro-Oeste, em vegetação de cerrado, e Norte, nas campinaranas e vegetações savanóides no domínio amazônico.

$\mathrm{O}$ gênero foi publicado por Linnaeus $\mathrm{f}$. (1782), em homenagem a um viajante na América, de sobrenome Amason (Moldenke 1939). No entanto, o primeiro nome proposto para o gênero foi Taligalea (Aublet 1775), o qual teria prioridade como nome genérico. Entretanto, o nome Amasonia foi denominado nomen conservandum pelo Código Internacional de Nomenclatura Botânica (Briquet 1935).
Amasonia inclui ervas, subarbustos e arbustos com folhas alternas, raro subopostas, inflorescências com eixo principal indeterminado e eixos laterais determinados, címulas subentendidas por brácteas coloridas e flores amareladas ou brancas, além de grãos de pólen elípticos a redondo-triangulares com a membrana do colpo rompendo-se irregularmente (Moldenke 1939; Troncoso 1974; Raj 1983; Judd et al. 2009).

Nos tratamentos clássicos, Amasonia foi reconhecido como membro de Verbenaceae (Schauer 1847, 1867; Bentham 1876; Briquet 1895; Junell, 1934). No entanto, mais recentemente, estudos filogenéticos em Lamiaceae e Verbenaceae (Cantino 1992a,b; Cantino et al. 1992; Abu-Asab \& Cantino 1992; Wagstaff et al. 1998; Steane et al. 2004, Judd et al. 2009), subsidiaram a transferência de Amasonia para Lamiaceae (subfamília Ajugoideae) levando-se em

\footnotetext{
${ }^{1}$ Parte da dissertação de Mestrado da primeira autora desenvolvida no Depto. Biologia da Universidade Federal Rural de Pernambuco, Brasil.

${ }^{2}$ Universidade Federal Rural de Pernambuco, 52171-900, Recife, PE, Brasil.

${ }^{3}$ Universidade Estadual de Feira de Santana, 44031-460, Feira de Santana, BA, Brasil.

${ }^{4}$ Universidade Federal de Goiás, 74001-970, Goiânia, GO, Brasil.

${ }^{5}$ Autor para correspondência: julyssantos@gmail.com
} 
consideração principalmente caracteríticas dos frutos (drupas com quatro mericarpos), estiletes (não persistentes) e do pólen (colunas granulares ramificadas na exina).

Amasonia foi revisado por Moldenke (1939) que considerou oito espécies e uma variedade. Posteriormente, Moldenke (1946, 1947, 1948, 1953, 1961, 1974, 1978, 1980, 1982) acrescentou informações sobre distribuição geográfica e tipificações. Ainda assim, algumas espécies não foram suficientemente caracterizadas e nenhuma delas foi ilustrada. Neste sentido, observou-se a necessidade de uma reavaliação com base em dados e coleções mais recentes.

Este estudo apresenta informações nomenclaturais e de tipificações, ilustrações dos caracteres vegetativos e reprodutivos relevantes, dados de distribuição geográfica e período de floração e frutificação.

\section{Material e Métodos}

O estudo foi fundamentado na observação de populações na região Centro-Oeste e no exame de aproximadamente 700 exsicatas provenientes dos seguintes herbários nacionais: CEN, CESJ, EAC, ESA, HEPH, HRB, HST (não indexado), HUEFS, HUFMT, IAC, INPA, IPA, MBM, MG, PEUFR, SP, UFG, TEPB, UB, UEC e VIC (Holmgren et al. 1990).

A identificação das espécies foi embasada nos protólogos das mesmas e em imagens de coleções-tipo, além de bibliografias especializadas e em materiais herborizados. Os nomes dos autores seguem Brummitt \& Powell (1992) e os nomes das obras, Stafleu \& Cowan (1976). A designação das terminologias das estruturas vegetativas e reprodutivas seguiu Rua (1999), Lawrence (1973), Radford et al. (1974) e Harris \& Harris (2001).

Comentários sobre a distribuição geográfica das espécies resultaram das informações dos rótulos das exsicatas e na consulta da literatura especializada. Chave para identificação das espécies e estampas ilustrativas foram elaboradas com base nos principais caracteres vegetativos e reprodutivos de cada espécie.

\section{Resultados e Discussão}

Amasonia L. f. nom. cons. Supp. Pl. 48: 294. 1782. Taligalea Aubl. nom. rejic. Hist. Pl. Guiane 2: 625, t. 252. 1775. Diphystemma Neck. nom. supp. Neck., Elem. Bot. I:382.1790.

Ervas, subarbustos ou arbustos. Ramos cilíndricos a subquadrangulares, glabrescentes, puberulentos, pubescentes, velutinos, vilosos ou hirsutos. Folhas alternas, espiraladas, em geral agrupadas na porção basal dos ramos ou abaixo da inflorescência, formando uma roseta ou ao longo dos mesmos, subsésseis ou pecioladas, limbo foliar em geral oboval a oboval-oblongo, oblanceolado, oblongo-elíptico a elíptico ou oval, base usualmente atenuada, desde glabrescente a variadamente indumentada. Inflorescência tirsóide; címulas dicasiais 3-12-flores em disposição espiralada, às vezes reduzidas a uma única flor, subtendidas por uma bráctea foliácea, geralmente vermelha, subséssil ou peciolada, oval, elíptica, oblongo-lanceolada, oblongo-elíptica, oblonga, oblanceolada, obovadoelíptica ou oboval, glabrescente, puberulenta, pubescente ou velutina, base atenuada, glândulas discóides geralmente presentes; eixos secundários e terciários bibracteolados, bractéolas filiformes ou espatuladas, esverdeadas, róseas, vermelhas a amarronzadas, puberulentas a velutinas. Flores pediceladas, pedicelo bibracteolado, bractéolas filiformes; cálice persistente, tubular-campanulado ou campanulado, 5-laciniado, lacínios triangulares, lanceolados ou ovais, margem em geral inteira, raro sinuada; corola infundibuliforme, alva ou amarelada ou alvo-rósea, às vezes com estrias longitudinais, limbo 5-lobado, levemente 2-labiada, 4 lobos iguais, 1 distinto, este reduzido ou revoluto. Estames 4, didínamos, emergindo próximo da base do tubo da corola, exsertos, filetes cilíndricos ou achatados; anteras oblongas, sagitadas, dorsifixas e versáteis; tecas paralelas e deiscência rimosa. Ovário globoso, glabro, 2-carpelar, 4-locular, lóculos 1-ovulados; estilete terminal, filiforme, exserto, estigma bífido, segmentos estigmáticos desiguais. Fruto drupáceo, esverdeado quando imaturo, negro na maturidade, exocarpo suculento, endocarpo coriáceo, separandose em 4 (1-3 por aborto) mericarpos na maturidade, pirênios 1-seminados; sementes sem endosperma.

\section{Chave de identificação para as espécies de Amasonia}

1. Folhas com limbo linear, por vezes estreitamente espatulado 1. Amasonia angustifolia

1'. Folhas com limbo oboval-oblongo, oblanceolado, oblongo-lanceolado, oboval, oblongo, oblongo-elíptico a elíptico, oval ou lanceolado. 
2. Limbo foliar com margem inteira, repanda ou denticulada.

3. Face adaxial do limbo foliar púrpura (visível em material fresco); brácteas obovais ou obovadoelípticas; bractéolas do eixo secundário filiformes 7. A. obovata

3'. Face abaxial do limbo foliar púrpura (visível em material fresco); brácteas oblongas ou oblongoelípticas; bractéolas do eixo secundário espatuladas 6. A. lasiocaulos

2'. Limbo foliar com margem erosa, serreada ou crenada.

4. Ramos e folhas vilosos a hirsutos 5. A. hirta

4'. Ramos e folhas glabrescentes, puberulentos, pubescentes, ou veluitnos.

5. Cálice com glândulas pelúcidas (glândulas circundadas por adensamentos de tricomas); corola com estrias longitudinais, estas vináceas 2. A. arborea

5'. Cálice sem glândulas pelúcidas; corola sem estrias longitudinais.

6. Lacínios do cálice de margem inteira; corola amarelada.

7. Corola maior ou igual a $3,5 \mathrm{~cm}$ de comprimento 3. A. calycina

7'. Corola menor que $3 \mathrm{~cm}$ de comprimento 4. A. campestris

6'. Lacínios do cálice de margem sinuada; corola alvo-rósea 8. A. spruceana

Amasonia angustifolia Mart. \& Schauer in D.C., Prodr. 11: 678. 1847. Taligalea angustifolia (Mart. \& Schauer) Kuntze, Revis. Gen. P1. 2: 509. 1891.

Fig. 1a-d

Erva ou subarbusto $30-40 \mathrm{~cm}$. Ramos 1-4 mm diâm., vináceos, cilíndricos, glabrescentes ou densamente pubescentes, tricomas hialinos, antrorsos; internós $0,8-5,9 \mathrm{~cm}$ compr. Folhas em geral agrupadas na porção superior dos ramos; pecíolo 1,5-8 mm compr., cilíndrico, pubescente; limbo $1,1-7,1 \times 0,3-1 \mathrm{~cm}$, cartáceo, linear, ou mais raramente estreitamente espatulado, discolor, face adaxial verde-escura, face abaxial verde-clara, ambas glabrescentes, raras glândulas discóides, base atenuada, margem em geral inteira, raramente erosa com dentes reduzidos, ápice agudo, nervura principal discretamente proeminente, nervuras secundárias e terciárias impressas. Inflorescência pauciflora, címulas reduzidas a uma única flor; pedúnculo 1-2 $\mathrm{mm}$ diâm., 7,1-13,5 cm compr., cilíndrico, às vezes anguloso, discretas estrias longitudinais, verdeavermelhado, pubescente; raque $7-14 \mathrm{~cm}$ compr., cilíndrica, avermelhada, pubescente; brácteas 0,8 $1,2 \times 0,3-0,6 \mathrm{~cm}$, membranáceas, ovais, às vezes elípticas, avermelhadas, pubescentes, tricomas adensados próximo à nervura central e margens, glândulas ausentes, margem erosa, ápice agudo, às vezes cuspidado; eixo secundário $2-4 \mathrm{~mm}$ compr., pubescente, bractéolas 2-3 mm compr., vermelhas, filiformes, pubescentes; pedicelo 1-3 mm compr., verde-avermelhado, pubescente, bractéolas 2-3 $\mathrm{mm}$ compr., vermelhas, pubescentes. Cálice 4-7 × 3-6 mm, tubular-campanulado, cartáceo, verde a vermelho, externamente pubescente a glabrescente, internamente glabro; tubo 2-4 mm compr.; lacínios 2-4,5 × $1 \mathrm{~mm}$, triangulares, margem inteira, ápice agudo, raras glândulas discóides. Corola 1,2-2,3 cm compr., amarelada; tubo $0,8-1,7 \mathrm{~cm}$ compr., externamente pubescente, internamente glabro; lobos 4-6 × 2,5-5 mm, ovais a lineares, externamente pubescentes, internamente glabros. Estames inseridos 5-6 mm da base, filetes 1,7-2,3 cm (os menores), 1,9-2,8 cm (os maiores), glabros, achatados; anteras 2,9-3 × 0,4 $\mathrm{mm}$. Ovário 2-2,5 $\times 2 \mathrm{~mm}$; estilete 2-3 cm compr., alvo, achatado, glabro; segmentos estigmáticos ca. 0,3-0,4 mm compr. Fruto ca. $1 \times 1$ $\mathrm{cm}$; mericarpos 4, sementes não observadas.

Material examinado: AMAZONAS: Humaitá, 27.XI.1966, G.T. Prance et al. 3370, (INPA); GOIÁS: 7 .XII. 1973, fl., J.A. Rizzo 9456 (UFG); 9.I.1974, fl., J.A. Rizzo 9513 (UFG); 8.II.1984, fl., J.A. Rizzo 9580 (UFG); Teresina de Goiás, 23.II.2003, fr., F. França et al. 4652 (HUEFS); MARANHÃO: Balsas, 7.XII.1980, P. Martins \& E. Nunes (EAC-9468); Carolina, 16.I.2008, fl. e fr., $G$. Pereira-Silva \& G.A.Moreira 12721 (CEN), 30.IX.2009, f1., G. Pereira-Silva et al. 14895 (PEUFR); MATO GROSSO: São Félix do Araguaia, 21.III.1997, V.C. Souza et al. 14827 (ESA,UFMT); PARÁ: Cachimbo, 1621.V.1955, W. Bockermann 287 (HST); TOCANTINS: Araguatins, 20.XI.2003, fl., A.H. Salles et al. 2688 (HEPH); Arraias, 10.V.1991, fl., G. Hatschbach \& J.M. Silva 56031 (ESA); Itacajá, 13.X.2000, fl. e fr., A.A. Santos et al. 783 (CEN); Palmeirópolis, 25.I.2008, fl. e fr., G. Pereira-Silva \& G.A. Moreira 12897 (PEUFR), 29.II.2008, fl. e fr., J.B. Pereira \& G.A. Moreira 160 (PEUFR); Paranã, 29.III.2004, A.C. Sevilha et al. 3953 (CEN); Taipas do Tocantins, 15.I.2008, fl., J.F.B. Pastore et al. 2419 (CEN).

Espécie endêmica do Brasil, ocorrendo nas Regiões Norte (AM, PA e TO), Nordeste (MA) e 

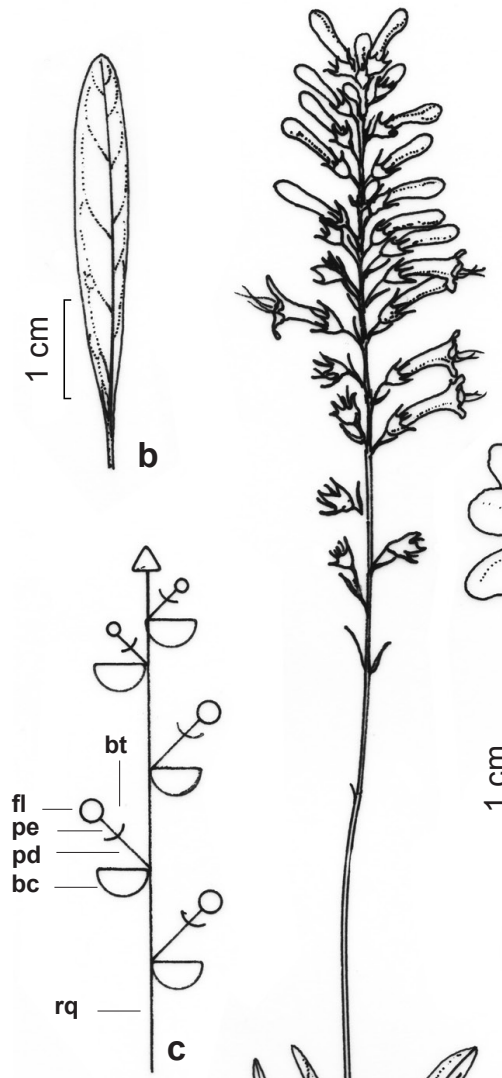

네
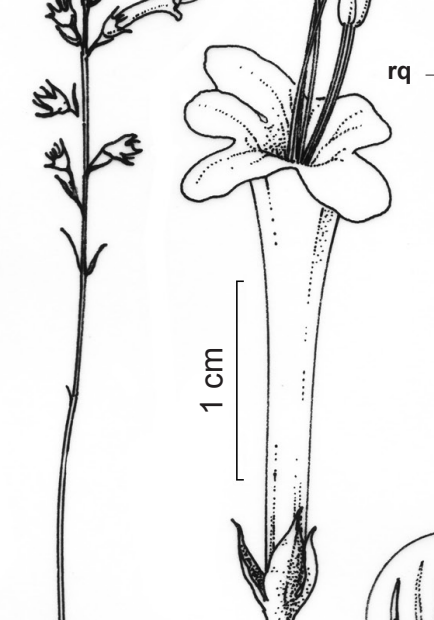

\section{$\triangle$}


Centro-Oeste (MT e GO), habitando em cerrado sensu stricto, campo limpo e campo rupestre, preferencialmente em áreas de solos arenosos ou alagáveis, em altitudes entre 150-425 m. Floresce entre os meses de setembro e maio.

Amasonia angustifolia é facilmente reconhecível em campo por suas folhas lineares ou estreitamente espatuladas, címulas dicasiais reduzidas a uma única flor, brácteas diminutas $(0,8$ $1,2 \times 0,3-0,6 \mathrm{~cm})$ e cálice tubular-campanulado com lacínios triangulares. O espécime tipo foi obtido por George Gardner, em 1837, com holótipo provavelmente em $\mathrm{M}$ e isótipos em $\mathrm{B}, \mathrm{E}, \mathrm{F}, \mathrm{G}, \mathrm{K}$, NY, P, US, V. No entanto, existe divergência quanto à data em alguns de seus isótipos; no espécime depositado no Field Museum a data de coleta que consta na etiqueta é 1841; no The New York Botanical Garden Herbarium o rótulo de outro isótipo mostra que a coleta fora realizada entre os anos de 1836 e 1841.

Amasonia arborea Kunth, Nov. Gen. Sp. ( $4^{\mathrm{a}}$ ed.) 2: 253.1817 [1818].

Fig. 1e-j

Subarbusto 0,4-1,5 m. Ramos 4-9 mm diâm., castanhos, subquadrangulares, às vezes cilíndricos, densamente pubescentes, tricomas castanhos, raras pontuações negras; internós $0,2-6,9 \mathrm{~cm}$ compr. Folhas em geral agrupadas na porção superior dos ramos; pecíolo 0,2-1,1 cm compr., cilíndrico, densamente pubescente; limbo 9,2-20,5 × 2,7-7,3 $\mathrm{cm}$, membranáceo ou cartáceo, obovado-oblongo a oblanceolado, discolor, face adaxial verdeescura, puberulenta ou pubescente, face abaxial verde-clara, glabrescente a pubescente, raras pontuações negras, base longamente atenuada, margem serreada, às vezes erosa, ápice agudo, raro obtuso, nervura principal proeminente, não vináceas, nervuras secundárias e terciárias levemente proeminentes. Inflorescência pauciflora a multiflora; címulas 3-7 flores; pedúnculo 3-6 mm diâm., 11-25,5 cm compr., subquadrangular, castanho-claro, densamente pubescente, às vezes velutino; raque $8-29,5 \mathrm{~cm}$ compr., cilíndrica a angulosa, castanha, densamente pubescente; brácteas 1,3-2 × 0,6-1,3 cm, membranáceas a cartáceas, elípticas ou ovais, discolores, face adaxial vermelha, face abaxial verde, puberulentas a pubescentes, glândulas discóides presentes, margem denticulada, ápice agudo, às vezes curtoacuminado; eixo secundário 2-8 $\mathrm{mm}$ compr., densamente pubescente; bractéolas ca. $3 \mathrm{~mm}$ compr., castanhas a avermelhadas, filiformes, puberulentas; eixo terciário 5-6 mm compr., castanho, densamente pubescente, bractéolas ca. $5 \mathrm{~mm}$ compr., castanhas a avermelhadas, puberulentas; pedicelo 4-5 mm compr., castanho a avermelhado, densamente pubescente, bractéolas 3-5 mm compr., castanhas a avermelhadas, densamente pubescentes. Cálice $0,8-1,2 \times 0,5-0,8$ $\mathrm{cm}$, campanulado, membranáceo a cartáceo, vermelho-esverdeado, externamente pubescente, internamente glabrescente, glândulas discóides pelúcidas presentes; tubo $3-5 \mathrm{~mm}$ compr.; lacínios 5-8 × 2-2,5 mm, ovais, margem inteira, ápice acuminado. Corola 2,5-3,1 cm compr., amarelada com estrias longitudinais vináceas; tubo 2,4-2,5 cm compr., externamente pubescente a velutino, internamente glabro; lobos 3-5 × 2-4 $\mathrm{mm}$, ovais ou ovado-triangulares, externamente pubescentes a velutinos, internamente glabros. Estames inseridos ca. $8 \mathrm{~mm}$ da base (os maiores), a ca. $9 \mathrm{~mm}$ da base (os menores), filetes ca. 2,6 $\mathrm{cm}$ compr. (os menores), ca. $3 \mathrm{~cm}$ compr. (os maiores), pubescentes a velutinos na porção basal, glabrescentes nas demais partes, achatados; anteras $2-2,5$ por $0,5 \mathrm{~mm}$. Ovário ca. $1,5 \times 2 \mathrm{~mm}$; estilete 3,1-3,4 cm compr., alvo, cilíndrico, glabrescente ou pubescente; segmentos estigmáticos 1,1-1,3 mm compr. (o menor), ca. 1,8 mm compr. (o maior). Fruto ca. 1,3 × 1,1 cm; mericarpos 4, 0,75-1,3 × $0,4 \mathrm{~cm}$; semente ca. $5 \times 0,2 \mathrm{~mm}$.

Material examinado: AMAPÁ: 1.VIII.1993, fr., $S$. Bridgewater et al. 61 (INPA); Oiapoque, 10.II.1950, R.L. Froés 25939 (IAC); AMAZONAS: Manaus, 27.II.1961, f1., W. Rodrigues \& J. Chagas 2173 (INPA); BAHIA: Barreiras, 4.II.2000, fl., N.G. Jesus et al. 829 (HRB, UEC); 4.II.2000, T. Ribeiro et al. 49 (UEC); CEARÁ: Crato, 21.II.1980, fr., P. Martins (EAC8056); Novo Oriente, 15.II.1991, fl., F.S. Araújo 280 (EAC), 16.II.1991, fr., F.S. Araújo 281 (EAC); Tianguá, 8.III.1981, A. Fernandes \& E. Nunes (EAC-9911); GOIÁS: Minaçu, 9.III.1992, fr., T.B. Cavalcanti et al. 1063 (CEN); MARANHÃO: Balsas, 7.XII.1980, P. Martins \& E. Nunes (EAC-9472), 9.III.1996, fr., G.P. Silva et al. 3461 (CEN, CESJ); Codó, 20.II.1982, fl. e fr., I. Gottsberger \& G. Gottsberger 25-20282 (CESJ); Loreto, 29.I.1970, fl., G. Eiten \& L.T. Eiten 10390 (SP); São Luís, V.1985, fl., M.F.P. Silva (HEPH58114); MATO GROSSO: 10.VII.1971, fl., J.R. Silva (IAC-22284); Luciara, 19.III.1997, fl., V.C. Souza et al. 14531 (ESA, UFMT); Tangará da Serra, 2.IV.2008, fl. e fr., C.A. Silva (UFMT-38655); PARÁ: 19.II.1970, fl., P. Cavalcante 2409 (MG); Breves, 20.IX.1968, fl., P. Cavalcante 1997 (MG); Marabá, 15.III.1984, fr., A.S.L. Silva et al. 1813 (MG); Santarém, 23.II.1986, fl., D.D. Ackerly 169 (INPA); Tucuruí, 17.III.1980, T. Plowman 
et al. 9699 (HRB); PIAUÍ: Brasileira, 27.II.1999, M.E. Alencar 508 (TEPB); Cabaceiras do Piauí, 19.V.2005, fl., R. Barros et al. 2265 (TEPB); Caracol, 26.I.2006, $R$. Barros et al. 2592 (TEPB); Elesbão Veloso, 15.V.1979, A.J. Castro (TEPB-934); Guaribas, 28.III.2007, fl., $R$. Barros et al. 2921 (TEPB); José de Freitas, 3.IV.2002, fl., M.E. Alencar et al. 1531 (TEPB); Ribeiro Gonçalves, 21.I.2005, fl. e fr., A.M. Miranda et al. 4782 (TEPB); São Raimundo Nonato, 11.II.1984, L. Empereire 2490 (TEPB); TOCANTINS: Darcinopolis, 21.II.2005, fl., G. Pereira-Silva et al. 9513 (CEN); Lagoa da Confusão, 24.III.1999, M.A. Silva et al. 4120 (CESJ, UFMT); Taguatinga, 26.I.2005, fl., J. Paula-Souza et al. 4718 (ESA), 26.I.2005, fl., J. Paula-Souza et al. 4766 (ESA). Material adicional examinado: BOLÍVIA. BOLÍVAR: Sucre, 13.VII.2000, fl., Fernández et al. 05-00351 (ESA).

Amasonia arborea apresenta ampla distribuição, ocorrendo nas Antilhas (Trinidad e Tobago) e América do Sul (Brasil, Bolívia, Colômbia, Venezuela, Guianas e Suriname), em altitudes variando entre 125 e 1400 m (Moldenke 1939, 1946, 1953, 1961, 1974, 1978, 1980, 1982). No Brasil, ocorre nos estados do Norte (Amazonas, Amapá, Pará e Tocantins), Nordeste (Maranhão, Piauí, Bahia e Ceará) e Centro-Oeste (Mato Grosso e Goiás), ocupando ambientes florestais como floresta amazônica (mata de terra firme), mata de galeria (no domínio do Cerrado) e florestas estacionais semideciduais e deciduais, em solos areno-argilosos, argilosos ou arenosos, associada a relevos planos e a locais úmidos e abertos. Floresce e frutifica em quase todos os meses do ano.

O exemplar tipo de Amasonia arborea foi coletado por Humboldt \& Bonpland 945 em 1-5.V.1800 no Amazonas, Venezuela, com holótipo provavelmente em $\mathrm{P}$ e isotipo em B-Willd. Esta espécie é facilmente recohecida pelas glândulas pelúcidas (glândulas circundadas por adensamentos de tricomas) no cálice e corola com estrias longitudinais vináceas. Apesar disto, tem sido frequentemente confundida com Amasonia calycina Hook (Aubl.) Moldenke ou A. campestris Hook (Aubl.) Moldenke nos herbários, como também na literatura, uma vez que Schauer (1847) tratou Amasonia arborea como sinônimo de $A$. punicea $\operatorname{Vahl}$ (=A. campestris) (Moldenke, 1939).

Amasonia calycina Hook. f., Bot. Mag. 113, t. 6915. 1887.

Fig. 2 a-e

Subarbusto, 0,4-1 m. Ramos 4-8 mm diâm., castanhos a esverdeados, cilíndricos a subquadrangulares, puberulentos a densamente pubescentes, tricomas hialinos; internós 0,2-4,4 cm compr. Folhas em geral agrupadas na porção superior dos ramos; pecíolo 0,3-2,5 cm compr., subquadrangular, puberulento ou pubescente; limbo 10,3-28,4 × 3,1-9,4 cm, membranáceo, discolor, elíptico a oblongo-lanceolado, face adaxial verde-escuro, glabrescente, às vezes puberulenta, face abaxial verde-claro, glabrescente, raras glândulas discóides em ambas as faces, base longamente atenuada, margem erosa, ápice agudo a curto-acuminado, nervuras principal e secundárias proeminentes, nervuras terciárias impressas. Inflorescência pauciflora; címulas 1-5 flores; pedúnculo 3-5 mm diâm., 0,7-3,3 cm compr., subquadrangular, verde a vináceo, puberulento ou pubescente; raque 10,3-39 $\mathrm{cm}$ compr., cilíndrica a angulosa, puberulenta ou pubescente; eixo secundário da inflorescência $0,5-1,6 \mathrm{~cm}$ compr., esverdeado, pubescente; brácteas 1-3,5 × 0,7-1,7 $\mathrm{cm}$, membranáceas, oblongo-lanceoladas, às vezes ovais, discolores, face adaxial vinácea, face abaxial vermelha, pubescentes, nervuras proeminentes na face abaxial, glândulas discóides numerosas, margem denticulada, ápice acuminado; eixo secundário $0,8-1 \mathrm{~cm}$ compr., pubescente, bractéolas $1-3,5 \mathrm{~mm}$, vermelhas, filiformes, pubescentes, eixo terciário ca. $8 \mathrm{~mm}$ compr., bractéolas $1-2 \mathrm{~mm}$ compr., vermelhas, pubescentes; pedicelo 0,8-1,1 cm compr., verde-vináceo, pubescente; bractéolas 1-2 mm compr., vermelhas, pubescentes. Cálice 0,7-1,3 × 0,5-0,9 cm, campanulado, com lacínios profundamente recortados, cartáceo, verdeavermelhado, externamente pubescente a velutino, tricomas mais adensados na margem e próximo à nervura central, internamente glabro; tubo $2-4$ mm compr.; lacínios $0,5-1 \times 0,2-0,4 \mathrm{~cm}$, ovais a lanceolados, margem inteira, ápice acuminado, às vezes caudado, raras glândulas discóides, glabros. Corola 3,7-4 cm compr., amarelada; tubo 3-3,3 cm compr., externamente pubescente a velutino, internamente glabro; lobos ca. $7 \times 5 \mathrm{~mm}$, ovadolineares, externamente pubescentes a velutinos, internamente glabros. Estames inseridos ca. 3,5 $\mathrm{mm}$ da base; filetes ca. 4,4 cm (os menores), ca. 4,5 $\mathrm{cm}$ (os maiores), velutinos na região basal, glabros nas demais partes, achatados; anteras, ca. $3 \times 1$ $\mathrm{mm}$. Ovário 1,5-1,8 × 1,6-2 mm; estilete 2,6-3 cm compr., castanho, cilíndrico, glabrescente; estigma profundamente bífido, segmentos estigmáticos 1-1,5 mm compr. (o menor), 1,2-1,8 mm compr. (o maior). Fruto 1,4-1,6 × 1,4-1,6 cm; mericarpos 4 , ca. $5 \times 4,5 \mathrm{~mm}$; sementes ca. $4 \times 2 \mathrm{~mm}$.

Material examinado: AMAZONAS: 20.II.1969, fl. e fr., G.T. Prance et al. 10120 (INPA); Manaus, 20.VIII.1995, 


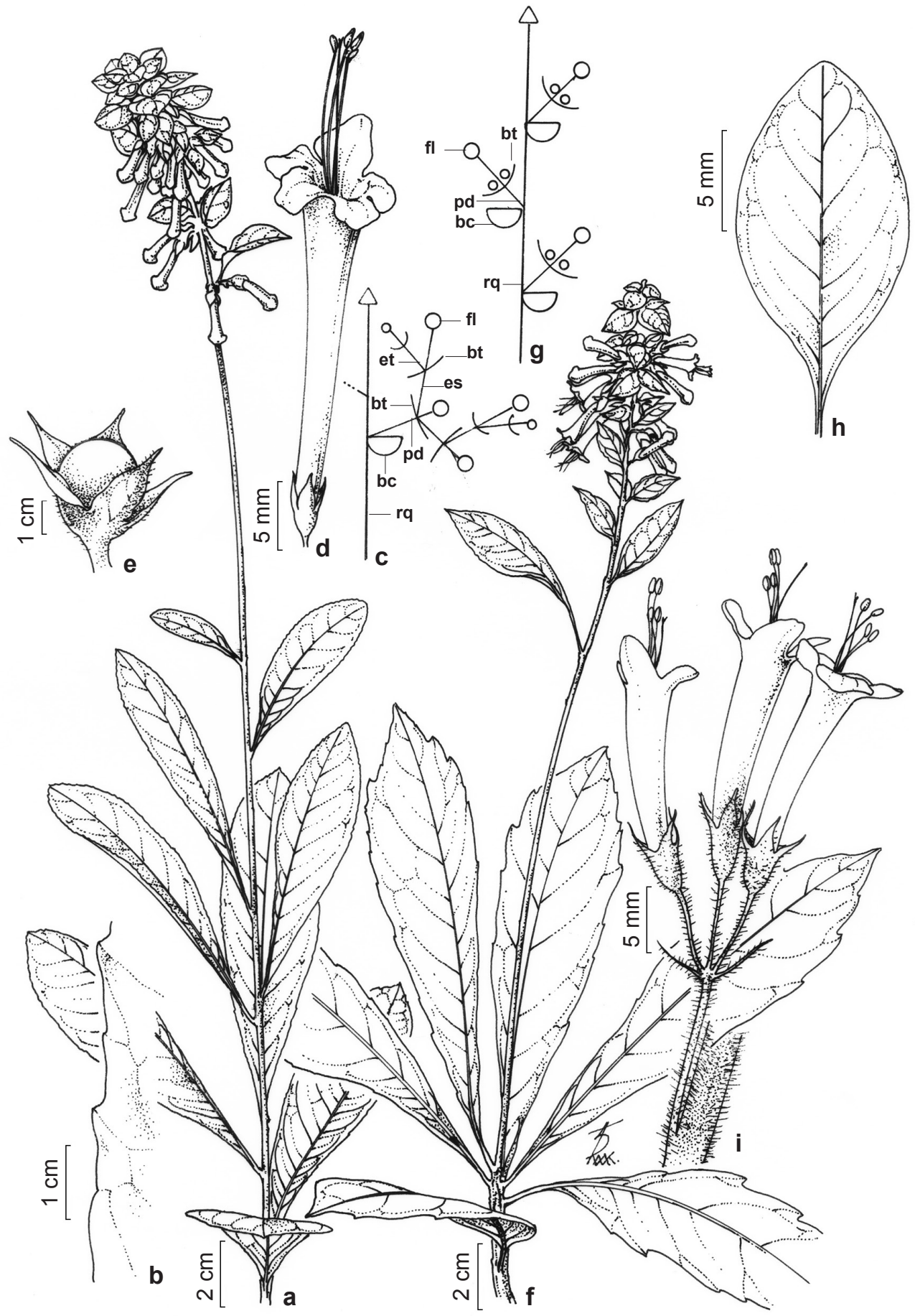

Figura 2 - a-e. Amasonia calycina Hook - a. hábito; b. margem foliar; c. diagrama da inflorescência (rq-raque, bc-bráctea, pd-pedúnculo, bt-bractéola, es-eixo secundário, et-eixo terciário, fl-flor); d. flor; e. fruto. (Ivanauskas et al. 1953). f-i. A. campestris (Aubl.) Moldenke - f. hábito; g. diagrama da inflorescência (rq- raque, bc-bráctea, pd-pedúnculo, bt-bractéola, fl-flor); h. bráctea; i. címula. (Rosa et al. 4192).

Figure 2 - a-e. Amasonia calycina Hook - a. habit; b. leaf margin; c. inflorescence diagram (rq-rachis, bc-bract, pd-peduncle, btbracteola, es-secondary axis, et-tertiary axis, fl-flower); d. flower; e. fruit. (Ivanauskas et al. 1953). f-i. A. campestris (Aubl.) Moldenke. f. habit; g. inflorescence diagram (rq- rachis, bc-bract, pd-peduncle, bt-bracteola, es-secondary axis, et-tertiary axis, fl-flower); h. bract; i. cymule. (Rosa et al. 4192). 
M. Nee 46248 (INPA); CEARÁ: Novo Oriente, 16.II.1991, fl., F.S. Araújo 280 (IPA); MARANHÃO: Barão de Grajaú, 24.III.1984, Orlandi 594 (IPA); Caxias, 17.I.1970, G. Eiten \& L.T. Eiten 10356 (SP); MATO GROSSO: São José do Rio Claro, 26.VI.1997, fl. e fr., N.M. Ivanauskas et al. 1953-A (ESA, UFMT); PARÁ: Maracanã, 2225.V.1994, fr., M.N. Bastos et al. 1665 (MG), 7.IX.1994, M.N. Bastos et al. 1767 (MG), 23.VIII.2007, fl., A.E.S. Rocha et al. 714 (MG); PIAUÍ: Brasileira, 26.III.1999, fl., M.E. Alencar 563 (TEPB); Guaribas, 21.III.2006, fl., G. Souza et al. 621 (TEPB); Monsenhor Gil, 28.II.2006, fl., L. Santos \& C. L. Santos 175 (TEPB), 19.III.2006, fl., L. Santos \& V. Azevedo 220 (TEPB).

Espécie registrada para Guiana e Brasil (Amazonas, Pará, Mato Grosso, Maranhão, Piauí e Ceará). Habita áreas de cerrado, floresta amazônica (matas de terra firme) sobre latossolo amarelo, regiões de contato entre florestas estacionais e florestas ombrófilas no Maranhão e florestas secundárias, predominando em áreas úmidas, próximo a rios e riachos e em clareiras, em altitudes de até $200 \mathrm{~m}$. Amasonia calycina floresce e frutifica entre os meses de maio e agosto.

Esta espécie pode ser reconhecida por apresentar folhas elípticas ou oblongo-lanceoladas de margem erosa, brácteas oblongo-lanceoladas ou ovadas e frutos maiores $(1,4-1,6$ por $1,4-1,6 \mathrm{~cm})$ que nas demais espécies de Amasonia. Hooker (1887) descreveu Amasonia calycina com base em um espécime oriundo da República da Guiana e cultivado no Royal Botanical Garden Kew, que teria sido coletada por D. Burcke e levado para a Europa em 1823 por Messrs. Veitch. Este espécime florido foi depositado no herbário K e ilustrado (prancha 6915) no Botanical Magazine (Moldenke 1939). Na monografia do gênero, Moldenke (1939) tratou a espécie baseando-se em seis espécimes de herbários, todos provenientes de material cultivado em jardins botânicos da Europa e dos Estados Unidos.

Amasonia campestris (Aubl.) Moldenke, Torreya 34: 8. 1934. Taligalea campestris Aubl. Hist. Pl. Guiane 2: 625, t. 252. 1775.

Fig. $2 \mathrm{f}-\mathrm{i}$

Subarbusto $0,2-1 \mathrm{~m}$. Ramos 4-7 mm diâm., castanhos a vináceos, cilíndricos a subquadrangulares, puberulentos a densamente pubescentes, tricomas hialinos; internós 0,4$7,2 \mathrm{~cm}$ compr. Folhas em geral agrupadas na porção mediana superior dos ramos; pecíolo 1,5-4 mm compr., cilíndrico a subquadrangular, densamente pubescente; limbo 6,5-18,5 × 2,2-5,4 $\mathrm{cm}$, membranáceo a cartáceo, discolor, oboval a oblanceolado, face adaxial verde-escura, pubescente a puberulenta ou glabrescente, raras glândulas discóides presentes, face abaxial verde-claro, pubescente a puberulenta ou glabrescente, base atenuada a cuneada, margem serreada, ápice agudo, nervura principal proeminente, vinácea, nervuras secundárias e terciárias levemente proeminentes. Inflorescência pauciflora, címulas 1-3 (-5) flores; pedúnculo 3-7 $\mathrm{mm}$ diâm., 7,9-21 cm compr., cilíndrico a subquadrangular, castanho-vináceo a castanho, densamente pubescente; raque 7,2-13 cm compr., cilíndrica a angulosa, castanho a vinácea, pubescente; eixo secundário da inflorescência 2-5 $\mathrm{mm}$, castanho-vináceo a castanho, densamente pubescente, raro velutino; brácteas $2-2,2 \times 1-2 \mathrm{~cm}$, membranáceas a cartáceas, elípticas, oblongas, às vezes oblanceoladas, róseas a vináceas, puberulentas ou pubescentes, glândulas ausentes, margem denticulada ou denteada, ápice mucronado, agudo ou acuminado; eixo secundário 4-8 mm compr., bractéolas 3-5 mm compr., vermelho-vináceas, filiformes, pubescentes a velutinas, tricomas castanhos, eixo terciário 3-5 mm compr., bractéolas 3-6 mm compr., vermelho-vináceas, pubescentes a velutinas, tricomas castanhos; pedicelo $3,5-8 \mathrm{~mm}$ compr., castanho a castanho-vináceo, densamente pubescente, bractéolas 3-6 mm compr., vermelhovináceas, pubescentes a velutinas. Cálice $6-9 \times$ 5-6 mm, campanulado, cartáceo, esverdeado com lacínios avermelhados, externamente puberulento ou pubescente, raro hirsuto, internamente puberulento, raro pubescente, glândulas ausentes; tubo 3,5-5 mm compr.; lacínios 1,5-2 × 1-1,5 mm, ovais, margem inteira, ápice acuminado. Corola 2-2,6 cm compr., amarelada; tubo 2-2,2 cm compr., externamente puberulento, internamente glabro; lobos 2,5-4 × 1,3-1,9 mm, estreitamente elípticos, externamente puberulentos, internamente glabros. Estames inseridos ca. $4 \mathrm{~mm}$ da base (os menores), a ca. $5 \mathrm{~mm}$ da base (os maiores); filetes 1,9-2,5 cm compr. (os menores), 2,4-3 cm compr. (os maiores), puberulentos na porção basal, glabros nas demais partes, achatados; anteras ca. $2 \times 0,5 \mathrm{~mm}$. Ovário 2-3 $\times 1,9 \mathrm{~mm}$; estilete $3-3,3 \mathrm{~cm}$ compr., alvo, achatado, glabrescente a pubescente; segmentos estigmáticos $0,7-0,9 \mathrm{~mm}$ (o menor), 1-1,2 mm (o maior). Fruto 8-9 × 5-6 mm; mericarpos 2-4, ca. $7 \times 5 \mathrm{~mm}$; sementes $5 \times 2,4-2,5 \mathrm{~mm}$.

Material examinado: AMAPÁ: Mazagão, 8.IV.1982, N.A. Rosa et al. 4192 (HRB, MG); BAHIA: Caetité, 10.II.1997, fr., M.L. Guedes et al. PCD 5339 (CESJ), 28.IV.2003, fl., M.L. Guedes et al. 10356 (HRB); Cocos, 10.XII.2001, M.L. Fonseca et al. 3038 (CESJ, HRB); Delfino, 9.III.1997, fl. e fr., P. Gasson et al. PCD 6176 (HRB); CEARÁ: 25.III.1936, P. Luetzelburg 25949 (IPA); Barbalho, 21.II.1963, L. Sampaio (IPA-13218); 
Crato, 28.III.2000, fr., E.B. Souza et al. 444 (EAC); Pacajus, 18.I.1998, E.B. Souza 171 (EAC); Redenção, 17.III.2002, V.C. Souza et al. 28672 (ESA); GOIÁS: Lizarda, 21.III.1978, J.S. Assis 31 (HRB); MARANHÃO: Balsas, 7.III.1996, fl., G.P. Silva et al. 3449 (CEN, CESJ); Barão de Grajaú, 26.I.1970, fl., G. Eiten \& L.T. Eiten 10375 (SP); São Luís, 22-23.X.1982, fl., K. Yamamoto et al. 14255 (UEC); Timon, 30.I.1981, A. Fernandes et al. (EAC-9606); PARÁ: Almeirim, 21.III.1986, fl., M.J.P. Pires \& N.T. Silva 825 (INPA, MG); Barcarena, 15.III.2002, fl., D.D. Amaral \& C.S. Rosário 241 (MG); Marabá, 10.III.1983, fl., C.A. Joly et al. 14865 (UEC); Marapanim, 16.VI.1991, M.N. Bastos et al. 1087 (MG); PERNAMBUCO: Exu, 6.V.1971, fl., E.P. Heringer et al. 610 (IPA), 11.II.1998, C. Ferreira (IPA-61980); PIAUÍ: Altos, 4.IV.1981, fr., A.J. Castro (TEPB-1502); Piripiri, 1.V.1978, A.B. Souza (TEPB-47).

Amasonia campestris ocorre na Venezuela, Trinidad e Tobago, Guianas, Suriname e Brasil (Moldenke 1939, 1946, 1947, 1948, 1953, 1961, 1978, 1980, 1982). Está amplamente distribuída nas Regiões Norte, Nordeste, Centro-Oeste e Sudeste do Brasil, ocorrendo desde o Amazonas até o Espírito Santo (Moldenke 1939, 1961, 1974, 1980), sendo encontrada no Amapá, Pará, Maranhão, Piauí, Ceará, Pernambuco, Bahia e Goiás. Esta espécie habita no domínio amazônico em locais sombreados e bordas de florestas, em latossolos, e em ambientes savanóides; no cerrado, cerradão e campo rupestre, e em áreas de transição entre caatinga e cerrado (Ceará), próximo a córregos, sobre solos arenosos, pedregosos e arenopedregosos. Amasonia campestris foi coletada em altidudes entre 130 e $1248 \mathrm{~m}$. Floresce e frutifica em todos os meses do ano.

Amasonia campestris assemelha-se morfologicamente com Amasonia arborea e $A$. hirta Benth devido compartilharem a forma das folhas (oboval a oblanceolada), margem foliar (serreada) e ainda o formato e ápice dos lacínios do cálice (agudo), porém diferencia-se das demais por apresentar limbo com nervura principal da face abaxial de coloração vinácea e címulas dicasiais com 1-3 flores. De acordo com Moldenke (1946, 1953, 1974, 1978, 1982), "herva de picapáo", "mendóca", "rabo de arara", "cacho vermelho", "cola de galo", "varita de San José" e "farfara roja" são listados como nomes vernaculares para $A$. campestris.

Amasonia hirta Benth., Ann. Nat. Hist. 2: 450-451. 1839.

Fig. 3a-f

Erva, subarbusto ou arbusto 0,3-1,8 m. Ramos 3-11 mm diâm., castanhos, esverdeados ou vináceos, cilíndricos, densamente vilosos a hirsutos, tricomas alaranjados; internós 0,6-7,5 cm compr. Folhas em geral agrupadas na porção superior dos ramos; pecíolo 1-8 $\mathrm{mm}$ compr., cilíndrico, às vezes subquadrangular, densamente viloso ou velutino; limbo 4,3-19,1 × 1,1-6,9 cm, cartáceo a raramente crasso, em geral concolor, oboval, às vezes oblongo, face adaxial verde escuro (quando discolor), vilosa a hirsuta, tricomas hialinos, glândulas discóides presentes, face abaxial verde clara (quando discolor), vilosa a hirsuta, tricomas hialinos, base atenuada, margem crenada, às vezes serreada, ápice agudo, às vezes obtuso, raramente arredondado, nervura principal proeminente, nervuras secundárias e terciárias impressas. Inflorescência pauciflora a multiflora, címulas 1-7 flores; pedúnculo 3-9 mm diâm., 2-12,9 cm compr., cilíndrico, verde a avermelhado, velutino; raque 7,5-34 cm compr., cilíndrica, esverdeada, avermelhada, densamente velutina; brácteas $0,8-3 \times 0,4-1,4 \mathrm{~cm}$, membranáceas a cartáceas, elípticas, às vezes obovais, avermelhadas, pubescentes a densamente velutinas, tricomas hialinos a alaranjados, glândulas discóides translúcidas presentes na face abaxial, margem inteira, ápice cuspidado, às vezes apiculado; eixo secundário $0,3-2 \mathrm{~cm}$ compr., pubescente a velutino, tricomas esbranquiçados; bractéolas 0,3-1 cm compr., esverdeadas a avermelhadas, filiformes, velutinas, tricomas esbranquiçados, eixo terciário $0,3-1 \mathrm{~cm}$ compr., bractéolas 3-7 mm compr., esverdeadas a avermelhadas, velutinas, tricomas esbranquiçados; pedicelo $0,5-1,5 \mathrm{~cm}$ compr., avermelhado, pubescente ou velutino, tricomas esbranquiçados, bractéolas 3-7 mm compr., esverdeadas a avermelhadas, velutinas, tricomas esbranquiçados. Cálice $0,6-1,8 \times 0,4-1,4$ $\mathrm{cm}$, campanulado, membranáceo, esverdeado, externamente velutino, tricomas hialinos, internamente esparsadamente velutino, glândulas discóides translúcidas basais; tubo 4-7 mm compr.; lacínios 4-8 × 2-5 mm, ovado-elípticos, às vezes triangulares, margem inteira, ápice acuminado ou cuspidado. Corola $2-3,5 \mathrm{~cm}$ compr., amarelada; tubo 1,9-3 cm compr., externamente velutino, tricomas hialinos, internamente glabro; lobos 3-5 $\times 8 \mathrm{~mm}$, ovais, externamente velutinos, tricomas hialinos, internamente glabros. Estames inseridos $7-8 \mathrm{~mm}$ da base do tubo da corola; filetes $2,3-2,5$ $\mathrm{cm}$ compr. (os menores), 2,8-3 cm compr. (os maiores), velutinos na porção basal, glabros nas demais partes, cilíndricos; anteras 2,5-3 × 0,5-1 $\mathrm{mm}$. Ovário 1,5-2 × 2-3 $\mathrm{mm}$; estilete ca. $3,1 \mathrm{~cm}$ 


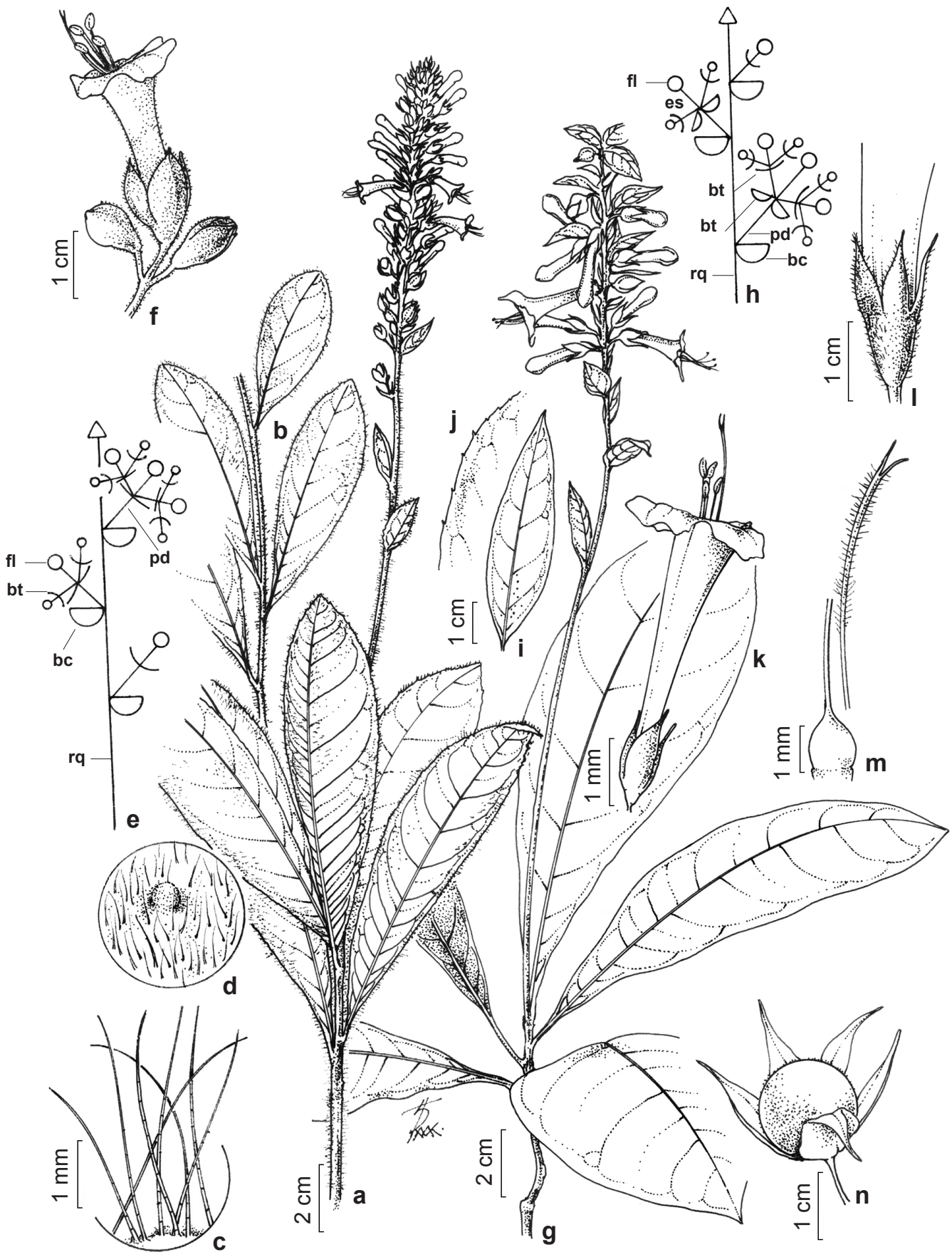

Figure 3 - a-f. Amasonia hirta Benth - a. hábito com folhas adensadas; b. hábito com folhas esparsadas; c. detalhe dos tricomas dos ramos; d. detalhe da glândula da superfície abaxial da folha; e. diagrama da inflorescência (rq-raque, bc-bráctea, bt-bractéola, pd-pedúnculo, fl-flor); f. címula. (Santos et al. 108). g-n. A. lasiocaulis Mart. \& Schauer ex Schauer-g. hábito; h. diagrama da inflorescência (rq-raque, bc-bráctea, pd-pedúnculo, bt-bractéola, es-eixo secundário, fl-flor); i. bráctea; j. detalhe da margem da bráctea; k. flor; 1. cálice; m. gineceu; n. fruto. (Miranda et al. 430).

Figure 3 - a-f. Amasonia hirta Benth - a. habit with condesed leaves; b. habit with sparse leaves; c. tricomas branches trichome detail; d. abaxial gland detail; e. inflorescence diagram (rq-rachis, bc-bract, bt-bracteola, pd-peduncle, fl-flower); f. cymule. (Santos et al. 108). g-n. A. lasiocaulis Mart. \& Schauer ex Schauer - g. habit; h. inflorescence diagram (rq-rachis, bc-bract, pd-peduncle, bt-bracteola, es-secondary axis, fl-flower); i. bract; j. bract margin detail; k. flower; 1. calyx; m. gynecium; n. fruit. (Miranda et al. 430). 
compr., branco-esverdeado, cilíndrico, glabro; segmentos estigmáticos, $0,8-1 \mathrm{~cm}$ compr. Fruto ca. $1 \times 0,7 \mathrm{~cm}$; mericarpos 4, ca. 1-0,3 cm; sementes $3,5 \times 1,5 \mathrm{~mm}$.

Material selecionado: AMAPÁ: Macapá, 17.III.1962, fl., J. Mattos \& N. Mattos 10136 B (UB). BAHIA: Caetité, 21.I.2003, fr., T.B. Cavalcanti et al. 3140 (CEN); DISTRITO FEDERAL: Brasília, 19.I.2010, fl., J.S. Santos et al. 112 (HEPH); Planaltina, 30.XII.1985, fl., M.F. Vieira 285 (VIC); GOIÁS: Alto Paraíso de Goiás, 4.II.1972, fl., J.A. Rizzo 7608 (UFG); Alvorada do Norte, 18.II.2003, fl. e fr., R.C. Mendonça et al. 5230 (HST, IBGE, UB); Anápolis, 27.II.1997, fr., Ferreira 3409 (UFG); Aparecida de Goiânia, 26.IV.2003, fr., J.F.B. Pastore \& B.A. Bringel 565 (CEN), Babaçulândia, 26.II.1980, fr., T. Plowman et al. (INPA 122685); Campo Alegre, 6.II.1994, fl., G. Hatschbach et al. 59888 (ESA); Chapadão do Céu, 6.I.1999, fr., M.A. Batalha 2728 (SP), 9.III.1999, fl., M.A. Batalha 3054 (UEC); Eclérica, 10.III.1974, fl. fr., E.P. Heringer 13170 (UB, UEC); Goiandira, 26.II.2005, fl., J.A. Rizzo et al. 12982 (UFG);; Leopoldo de Bulhões, 6.III.1997, fl., H.D. Ferreira 3451 (UFG); Minaçu, 21.III.1996, fl., B. Walter et al. 3291 (CESJ); Mineiros, 16.II.1995, fr., G.W. Salla 22 (UFG); Mossâmedes, 18.II.1994, fr., J.A. Rizzo 11036 (UFG); Pirenópolis, 18.I.2005, J. PaulaSouza et al. 4067 (ESA); São Gabriel, 1.III.2005, fl. e fr., A.H. Salles et al. 3703 (HEPH); Serra Geral de Goiás, 30.III.1966, fr., H.S. Irwin et al. 14296 (MG); Uruaçu, 12.IV.1972, J.A. Rizzo 7989 (UFG); MATO GROSSO: Alto Boa Vista, 22.III.1997, fr., V.C. Souza et al. 14937 (ESA); Alto Paraguai, 28.I.1995, B. Dubs 1802 (ESA); Barra do Garças, 24.III.1997, fr., G.F. Árbocz et al. 3585 (ESA, UFMT); Campo Novo Parecis, 26.II.1995, fl., M. Macedo \& R. Godinho 4078 (UFMT); Cuiabá, 23.III.1892, fl., J.R.B. Monteiro et al. 09 (UFMT); Nobres, 19.V.1997, V.C. Souza et al. 16495 (ESA); Poxoréu, 27.I.1986, fl., L. Andersson \& M. Hagberg 1592 (UB); Rio Brilhante, 15.II.1970, fl., G. Hatschbach 23618 (MBM); Várzea Grande, 3.II.1994, fr., M. Macedo $\&$ R. Godinho 3603 (INPA); MATO GROSSO DO SUL: Aquidauana, 12.XI.1996, fl., G.B. Santos et al. 26 (UB); Iguatemi, 8.II.1998, fl e fr., O.S. Ribas \& L.B.S. Pereira 2620 (MBM); Ponta Porã, 9.II.1993, fl., G. Hatschbach et al. 58783 (MBM); Rio Verde de Mato Grosso, 7.II.1975, fl., G. Hatschbach et al. 35942 (MBM). MINAS GERAIS: Ibiá, 2.III.1989, fl., B.M.T. Walter et al. 14 (UB); Indianópolis, 3.III.1986, G. Gottsberger \& J. Döring 126-3386 (CESJ); Ituiutaba, 6.II.1949, fl., A. Macedo 1611 (SP); Montes Claros, 9.III.1998, fl., G. Hatschbach et al. 67538 (MBM); Perdizes, 16.I.2003, fl., E.H. Amorim et al. 451 (UB); Prata, 15.I.2005, fl., J. Paula-Souza et al. 3858 (ESA); Uberlândia, 11.III.1962, fl. e fr., G. Eiten \& L.T. Eiten 3566 (CESJ, SP); PARÁ: Monte Alegre, 11.V.1953, D.A. Lima 53-1560 (IPA); TOCANTINS: Palmas, 17.III.1994, fr., F. Bucci et al. 135 (HEPH, UB).
Amasonia hirta possui distribuição no Paraguai (Moldenke 1961, 1982) e Brasil (Rondônia, Amapá, Pará, Tocantins, Mato Grosso, Distrito Federal, Goiás, Mato Grosso do Sul, Minas Gerais e Bahia), habitando ambientes florestais e de cerrado, em altitudes que variam de 530 a $1380 \mathrm{~m}$. Ocorre em clareiras dentro de floresta no domínio amazônico, mata de galeria, campo cerrado seco ou úmido, crescendo em locais arenosos com afloramentos rochosos, e em solos areno-argilosos periodicamente inundáveis. Floresce em todos os meses do ano e frutifica entre os meses de março e julho e entre dezembro e março.

Amasonia hirta foi descrita com base no material coletado por Pohl e Langsdorff s/n, no Brasil. Trata-se de uma espécie de fácil reconhecimento por ser a única a apresentar ramos e órgãos vilosos ou hirsutos com tricomas de coloração hialinoalaranjada. É muitas vezes confundida com alguns representantes da família Gesneriaceae, dos gêneros Gesneria L. e Sinningia Nees devido ao indumento de seus órgãos e aparência da porção florífera. De acordo com Moldenke (1974), A. hirta é popularmente conhecida como "mendoca".

\section{Amasonia lasiocaulos Mart \& Schauer ex Schauer,} Prodr. 11: 678. 1847. Fig. 3 g-n

Subarbusto ou arbusto 0,40-2,0 m. Ramos 0,4-1 cm diâm., esverdeados a castanhos, cilíndricos, às vezes subquadrangulares, pubescentes a vilosos, tricomas hialinos a róseos presentes em ramos, inflorescência e flores; internós 0,3-4,6 cm compr. Folhas em geral agrupadas na porção superior dos ramos; pecíolo 0,3-1 cm compr., cilíndrico, pubescente a velutino; limbo 15,9-38 × 5-11,7 $\mathrm{cm}$, membranáceo, discolor, oboval, às vezes oblanceolado, face adaxial verde, glabrescente, face abaxial púrpura, glabrescente, pontuações negras presentes, raras glândulas discóides próximo a nervura central, base atenuada, margem repanda, raro inteira, ápice agudo, curto acuminado, mais raramente arredondado, nervura principal muito proeminente, nervuras secundárias e terciárias levemente proeminentes. Inflorescência pauciflora a multiflora, címulas 1-7 flores (-12); pedúnculo 3-6 mm diâm., 13-24 cm compr., cilíndrico, às vezes subquadrangular, verde a marrom, velutino, tricomas róseos; raque 8,5-25,4 cm compr., cilíndrica, verde a marrom, velutina, tricomas róseos; brácteas 1,3-5,6 $\times$ 0,6-2,4 cm, membranáceas, oblongas, às vezes oblongo-elípticas, róseas a vináceas, glabrescentes, glândulas discóides próximo a nervura central, 
margem inteira ciliada, às vezes denticulado-erosa, com dentes esparsados, ápice agudo; eixo secundário 0,3-1,1 cm compr., verde-amarronzado, velutino, tricomas hialinos; bractéolas 6-7 × 3-4 mm compr., róseas a vermelhas, espatuladas, velutinas, tricomas hialinos; eixo terciário 3-9 mm compr., bractéolas ca. $1 \mathrm{~cm}$ compr., róseas a esbranquiçadas, velutinas; pedicelo 3-8 mm compr., verde-amarronzado, velutino, tricomas hialinos, bractéolas $0,6-1 \mathrm{~cm}$ compr., róseas a esbranquiçadas, velutinas. Cálice 0,9-1,1 × 0,7-0,9 cm, campanulado, membranáceo, esverdeado, externa e internamente velutino, tricomas hialinos, glândulas discóides translúcidas na base do cálice até a base dos lacínios; tubo 4-5 mm compr.; lacínios 4-5 × 1-1,5 mm, ovais, margem inteira, ápice agudo, mucronulado. Corola 3,6-4,4 cm compr., alvacenta a amarelada com estrias longitudinais cremes; tubo 3,3-4 cm compr., externamente velutino, às vezes glabro, internamente glabro; lobos ca. 4-5 $\times 3 \mathrm{~mm}$, ovado-elípticos, externamente velutinos, internamente glabros. Estames inseridos ca. 1,5 mm da base do tubo da corola; filetes 2,9-3,9 cm compr. (os menores), 3,3-4,3 cm compr. (os maiores), velutinos na porção basal, glabros nas demais partes, achatados; anteras 2-3 × $1 \mathrm{~mm}$. Ovário ca. $1 \times 1 \mathrm{~mm}$; estilete ca. 4,2 cm compr., alvo-hialino, cilíndrico, velutino, tricomas hialinos; segmentos estigmáticos, ca. $0,8 \mathrm{~mm}$ compr. (o menor), ca. $1 \mathrm{~mm}$ compr. (o maior), velutinos. Fruto ca. $9 \times 9 \mathrm{~mm}$; mericarpos 3-4, ca. $1 \times 0,6 \mathrm{~mm}$; sementes $5 \times 3 \mathrm{~mm}$.

Material examinado: ACRE: Cruzeiro do Sul, 8.III.1976, fl., J.R. Ramos \& G. Mota 345 (INPA); AMAZONAS: 27.V.1998, fr., M.A.D. Souza et al. 700 (INPA), 11.IX.2001, fl., A. Loureiro et al. (INPA-48258); 12.IX.2001, fr., F. Mello \& G. Mota 49A (INPA); 23.IX.2001, fl., O.S. Anjos 60 (INPA); Itacoatiara, 14.IX.2001, fl. e fr., E.A. Anunciação et al. 816 (SP); Manaus, 27.II.1961, fl., W. Rodrigues \& L. Coêlho 2170 (INPA), 5.IX.2001, fr., V.F. Kinupp \& F.N. Pereira 2019 (INPA), 6.IX.2001, fr., V.F. Kinupp 1785 (INPA), 7.IX.2001, M. Groppo Jr. et al. 922 (INPA), 13.IX.2001, fl. e fr., F. Mello \& L. Coêlho (INPA-3638), 16.IX.2001, fr., J.E.L.S. Ribeiro et al. 939 (INPA), 21.IX.2001, fl. e fr., W. Rodrigues \& J. Chagas 4410 (INPA), 21.IV.2004, fr., F.A. Carvalho 169 (INPA); Nova Prainha, 22.IX.2001, C.D. Mota \& L. Coêlho (INPA60630); Rio Mairé, 10.IX.2001, L.A. Maia et al. 440 (INPA); CEARÁ: Aratuba, 8.IX.2001, fr., E. Nunes \& P. Martins (EAC-8618); Barra do Corda, 9.IX.2001, fl., G. Eiten \& L.T. Eiten 10257 (SP); MARANHÃO: Buritirama, 15.IX.2001, fr., J. Arouck Ferreira \& C.A. Miranda 320 (HRB); Estreito, 7.III.2007, fl., G. Pereira-Silva \& G.A. Moreira 11230 (CEN); MATO GROSSO: 17.IX.2001, fl., J.G. Kuhlmann 1337 (SP); PARÁ: Bagre, 23.VI.2008, fl. e fr., G.F. Árbocz et al. (IAC 49969); Cruzeiro do Sul,
13.IV.1971, fl., G.T. Prance et al. 11782 (MG); Jacundá, 20.V.1997, fl., I.P. Miranda et al. 430 (INPA); Marabá, fl. e fr., P. Cavalcante 2184 (MG), 25.III.1977, fl., M.G. Silva 2864 (MG); 20.III.1984, fl., A.S.L. Silva et al. 1930 (MG); Moju, 13.VI.2002, J. Oliveira et al. 440 (MG); Oriximiná, 3.VI.1980, G. Martinelli 6756 (INPA); Palestina do Pará, 18.IV.2004, fl., G.P. Silva et al. 8835 (CEN); Portel, 22.VI.2008, fl., L.C. Bernacci et al. 4534 (IAC); Santarém, 1.IX.1998, fr., J.C. Costa 35-A (INPA); São Domingos do Capim, 5.VII.1974, fl. e fr., P. Cavalcante 3001 (MG); RONDÔNIA: 18.IX.2001, S. Romaniuc Neto et al. 654 (CESJ); 20.IX.2001, fl., S. Romaniuc Neto et al. 657 (SP); TOCANTINS: Itacajá, 7.V.2000, fl., A.A. Santos et al. 683 (CEN).

Amasonia lasiocaulos distribui-se na Venezuela, Colômbia, Peru, Guianas e Brasil em altitudes que variam entre 200 e $700 \mathrm{~m}$ (Moldenke 1939, 1947, 1953, 1961, 1974, 1978, 1980, 1982). No Brasil está presente nos estados de Rondônia, Acre, Amazonas, Amapá, Pará, Tocantins, Mato Grosso, Maranhão e Ceará, associada principalmente a ambientes florestais do domínio amazônico, habitando também áreas de campinaranas altas, capoeiras e carrasco (Ceará). Cresce à beira de estradas e locais pantanosos, sobre solos argilo-pedregosos, arenosos, argilosos úmidos e solos de origem calcária. Floresce entre janeiro e setembro e frutifica entre os meses de fevereiro e junho e em novembro.

É uma espécie facilmente reconhecível devido à presença de ramos pubescentes a velutinos com tricomas hialinos a róseos, limbo foliar com a face adaxial verde e a face abaxial púrpura de margem inteira ou repanda, brácteas membranáceas oblongas ou oblongo-elípticas, róseas a vináceas e bractéolas do eixo secundário espatuladas.

Amasonia obovata Gleason, Bull. Torrey Bot. Club 58: 463. 1931 .

Fig. $4 a-c$

Subarbusto ou arbusto 0,3-2,5 m. Ramos 0,4-1,2 cm diâm., castanhos, subquadrangulares, pubescentes a vilosos, tricomas castanhos na inflorescência e flores; internós 0,4-1,2 cm compr. Folhas em geral agrupadas na porção superior dos ramos; pecíolo 0,3-2,4 cm compr., subquadrangular, glabrescente, pubescentes ou velutinos, tricomas castanhos; limbo 17-36 × 5,1-10 cm, membranáceo a cartáceo, discolor, oblongo-lanceolado, às vezes oblongo-elíptico, face adaxial púrpura, glabrescente, pontuações negras presentes, face abaxial verde, glabrescente, glândulas discóides próximo a nervura central, base atenuada, margem inteira, às vezes denticulada, 
ápice agudo, acuminado ou cuspidado, nervuras principal e secundárias proeminentes, nervuras terciárias impressas. Inflorescência pauciflora a multiflora, címulas 1-12 flores; pedúnculo 2-3 mm diâm., 3-21,5 cm compr., cilíndrico, castanho, velutino; raque $8-26,1 \mathrm{~cm}$ compr., cilíndrica, castanha, velutina; brácteas $1,5-3,1 \times 0,6-3,1 \mathrm{~cm}$, cartáceas, obovais, às vezes obovado-elípticas, róseas a vermelhas, glabrescentes, glândulas discóides presentes, margem inteira a crenulada, ápice rotundo-mucronado; eixo secundário 4-8 mm compr., bractéolas $1-1,5 \mathrm{~mm}$ compr., marrons, filiformes, velutinas, tricomas castanhos, eixo terciário $0,3-1,1 \mathrm{~cm}$ compr., bractéolas ca. $1,5 \mathrm{~mm}$, marrons, velutinas, tricomas castanhos; pedicelo 4-8 mm compr., castanho, velutino, bractéolas 1-1,5 mm compr., marrons, velutinas, tricomas castanhos. Cálice 1,1-1,2 × 0,9-1 cm, largamente campanulado, cartáceo, vináceo, externamente pubescente a velutino, internamente glabro; tubo 4-5 mm compr.; lacínios 6-7 × 3-4 mm compr., triangulares, margem inteira, ápice acuminado a cuspidado, glândulas discóides na base. Corola 2,9-3,3 cm compr., alvo-alaranjada, com estrias longitudinais cremes; tubo 2,3-2,9 cm compr., externa e internamente glabro; lobos ca. $5 \times 4$ $\mathrm{mm}$, ovado-oblongos, externamente glabros a glabrescentes, internamente glabros. Estames inseridos ca. $4 \mathrm{~mm}$ da base do tubo; filetes ca. $2,8 \mathrm{~cm}$ compr. (os menores), ca. $3 \mathrm{~cm}$ compr. (os maiores), velutinos na porção basal, glabrescentes nas demais partes, achatados; anteras 2,5-2,7×0,5 mm. Ovário ca. $1,5 \times 1,5 \mathrm{~mm}$; estilete ca. $3,2 \mathrm{~cm}$ compr., alvo, cilíndrico, glabrescente; segmentos estigmáticos ca. $5 \mathrm{~mm}$. Fruto $0,8-1 \times 0,8-1 \mathrm{~cm}$; mericarpos 3-4, ca. 1 $\times 0,4 \mathrm{~cm}$; sementes ca. $1 \times 0,2 \mathrm{~cm}$.

Material examinado: AMAZONAS: Borba, 26.IX.2001, A. Henderson et al. 360 (INPA); Humaitá, 28.IX.2001, L.O.A. Teixeira et al. 1205 A(INPA); Manaus, 25.IX.2001, fr., C. Dick 171 (INPA); MATO GROSSO: Sinop, 27.IX.2001, fl., N.M. Yoshitak \& G.S. Suli 10 (UFMT); PARÁ: Altamira, 10.XII.2007, fl., R.P. Salomão 993 (MG); Itaituba, 24.IX.2001, fl., I.L. Amaral et al. 1290 (INPA); Marabá, 28.I.1985, fl., O.C. Nascimento \& R.P. Bahia 1034 (MG), Marabá, 23.IV.1985, fl., N.A. Rosa et al. 4700 (MG); PIAUÍ: Batalha, 18.III.2006, fl., $L$. Oliveira et al. 39 (TEPB); Guaribas, 29.V.2008, fr., R. Barros et al. 3245 (TEPB); TOCANTINS: Ananas, 15.IV.2004, fl., G. Pereira-Silva et al. 8576 (CEN).

Amasonia obovata apresenta distribuição na Venezuela (Moldenke 1939, 1947, 1978) e no Brasil (Amazonas, Pará, Piauí, Tocantins e Mato Grosso). Habita principalmente o interior de florestas de terra firme sobre solos argilo-pedregosos, além de cerrados nos estados do Piauí e Mato Grosso, em altitudes entre 125-1095 m. Floresce entre os meses de agosto e janeiro e frutifica no mês de setembro.

Amasonia obovata, descrita com base no material Tate 902, oriunda de Aguita, Venezuela, diferencia-se das demais espécies por ser a única espécie do gênero a apresentar brácteas amplamente obovadas ou obovado-elípticas, limbo foliar com face adaxial púrpura e face abaxial verde e corola branco-alaranjada com estrias longitudinais cremes. Assemelha-se à A. lasiocaulos devido ao seu comprimento $(0,3-2,5 \mathrm{~m})$, margem (inteira, repanda ou denticulada) e indumento (glabrescente) de suas folhas.

Amasonia spruceana Moldenke, Repert. Spec. Novarum Regni Veg. 37: 213. $1934 . \quad$ Fig. 4d-i Subarbusto ca. $1 \mathrm{~m}$. Ramos 4-8 mm diâm., vináceos, cilíndricos, às vezes subquadrangulares, pubescentes a velutinos, tricomas castanhos; internós $0,5-3,5 \mathrm{~cm}$ compr. Folhas em geral distribuídas ao longo dos ramos; pecíolo $0,7-1,5$ $\mathrm{cm}$ compr., subquadrangular, pubescente a velutino, tricomas castanhos; limbo 5,3-15,6 × 2-5,3 cm, cartáceo a crasso, discolor, oval, às vezes lanceolado, face adaxial verde-escuro, pubescente, pontuações negras presentes, face abaxial verde-claro, glabrescente a pubescente, glândulas discóides presentes principalmente próximo a nervura central, base longamente atenuada, margem serreada, ápice agudo, nervuras principal, secundárias e terciárias proeminentes. Inflorescência multiflora; címulas 1-12 flores; pedúnculo 2-5 mm diâm., 2-10 $\mathrm{cm}$ compr., cilíndrico, castanho a vináceo, pubescente a velutino, tricomas castanhos; raque $6,5-25,5 \mathrm{~cm}$ compr., cilíndrica, castanha a vinácea, velutina, tricomas castanhos; brácteas $2-2,7 \times 0,5-1,1 \mathrm{~cm}$, cartáceas, ovais, às vezes elípticas, discolores, face adaxial vermelha, face abaxial verde, pubescentes a velutinas, glândulas discóides presentes, principalmente próximo às margens, margem denticulada, ápice agudo a cuspidado; eixo secundário ca. $1 \mathrm{~cm}$ compr., cilíndrico, velutino, bractéolas 2-6 $\mathrm{mm}$ compr., castanhas, filiformes, velutinas, tricomas castanhos, eixo terciário ca. 5 $\mathrm{mm}$ compr., cilíndrico, marrom, velutino, tricomas castanhos, bractéolas 2-3 mm compr., castanhas, velutinas, tricomas castanhos; pedicelo $0,7-1,2 \mathrm{~cm}$ compr., cilíndrico, velutino, bractéolas $2-5 \mathrm{~mm}$ compr., castanhas, velutinas, tricomas castanhos. Cálice 0,9-1,1 × 0,4-0,6 cm, campanulado, 


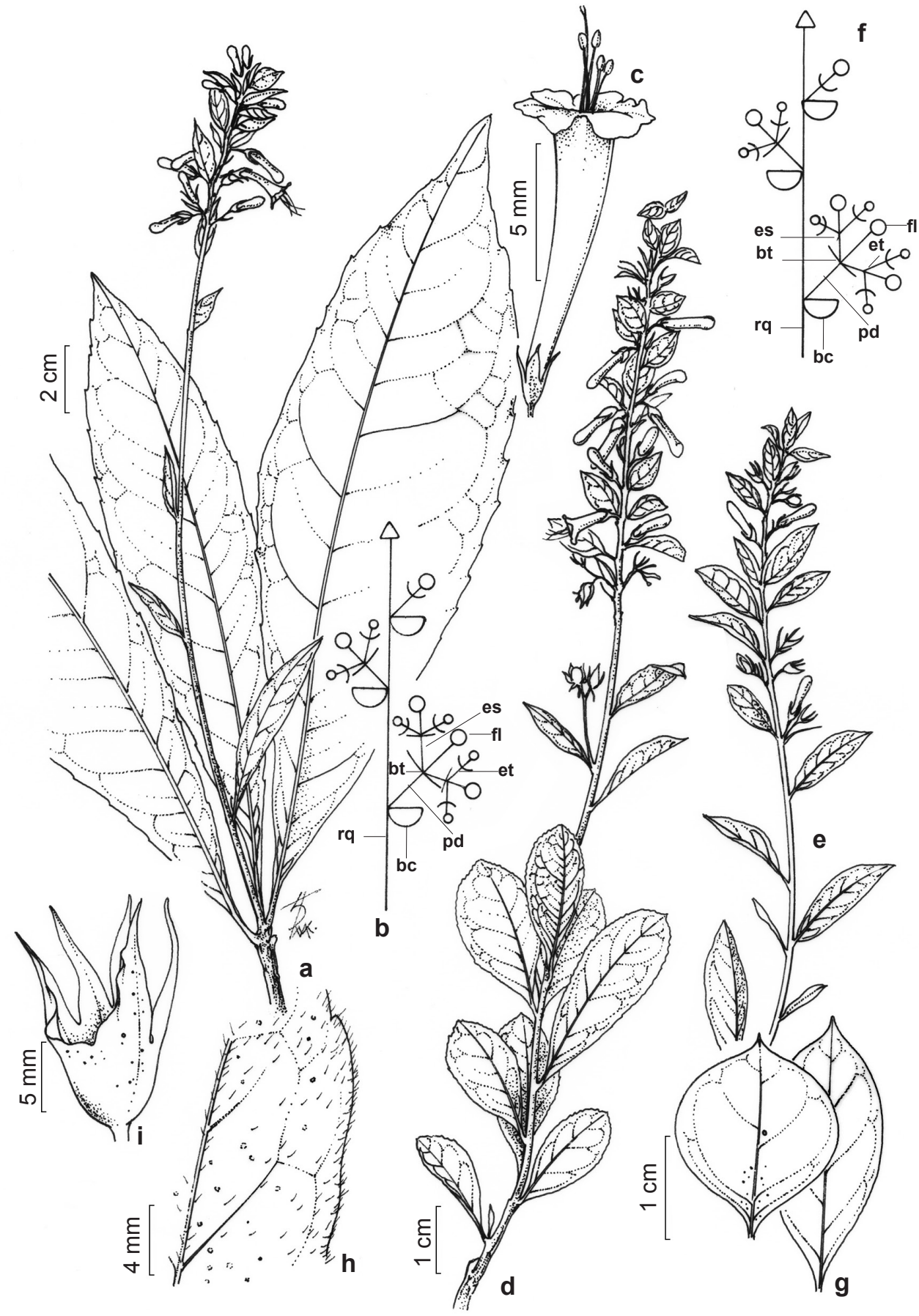

Figura 4 - a-c. Amasonia obovata Gleason - a. hábito; b. diagrama da inflorescência (rq-raque, bc-bráctea, pdpedúnculo, bt-bractéola, es-eixo secundário, et-eixo terciário, fl-flor); c. flor. (Yoshitak \& Suli 10). d-i. A. spruceana Moldenke - d. hábito com folhas adensadas; e. hábito com folhas esparsadas; f. diagrama da inflorescência (rq-raque, bc-bráctea, pd-pedúnculo, bt-bractéola, es-eixo secundário, et-eixo terciário, fl-flor); g. brácteas; h. detalhe da margem da bráctea; i. cálice. (Fonseca et al. 446).

Figure 4 - a-c. Amasonia obovata Gleason. a. habit; b. inflorescence diagram (rq-rachis, bc-bract, pd-peduncle, bt-bracteola, es-secondary axis, et-tertiary axis, fl-flower); c. flower. (Yoshitak \& Suli 10). d-i. A. spruceana Moldenke. d. habit with condesed leaves; e. habit with sparse leaves; f. inflorescence diagram (rq-rachis, bc-bract, pd-peduncle, bt-bracteola, es- secondary axis, et-tertiary axis, fl-flower); g. bracts; h. bract margin detail; i. calyx. (Fonseca et al. 446). 
membranáceo, esverdeado, externa e internamente velutino, tricomas hialinos, raras glândulas discóides; tubo 2-5 mm compr.; lacínios 6-7 × 2-3 mm compr., lanceolados, margem sinuada, ápice agudo a acuminado. Corola 2,8-3,2 cm compr., alvo-rósea, glabra; tubo 2,3-2,7 cm compr.; lobos $1,1-5,7 \times 2-3 \mathrm{~mm}$, ovais ou ovado-triangulares, externa e internamente glabros. Estames inseridos ca. 5,2 $\mathrm{mm}$ da base do tubo da corola; filetes ca. $4 \mathrm{~cm}$ compr. (os menores), ca. 4,4 cm compr. (os maiores), glabros, achatados; anteras $2,3 \times 1 \mathrm{~mm}$. Ovário ca. $2 \times 2 \mathrm{~mm}$; estilete ca. $4 \mathrm{~cm}$ compr., alvo, cilíndrico, glabro; segmentos estigmáticos ca. 0,7 $\mathrm{mm}$ compr. Fruto 6,5-9 × 6-9 mm; mericarpos 4, ca. 5-6 × $4 \mathrm{~mm}$; sementes 3-4 × $2 \mathrm{~mm}$.

Material examinado: BAHIA: 4.III.1974, fr., R.M. Harley et al. 16707 (IPA); Seabra, 20.III.1980, fr., G.C.P. Pinto 136/80 (HRB), 19.III.1985, fr., W.N. Fonseca \& Araújo 446 (HRB); PARÁ: 24.VIII.1959, M. Kuhlmann \& S. Jimbo 114 (CESJ, SP); Paragominas, 6.VIII.1977, C. Tokarnia 1356 (INPA).

Amasonia spruceana ocorre na Colômbia, Venezuela em altitude variando entre 200 e $800 \mathrm{~m}$ (Moldenke 1939, 1947, 1948, 1961, 1947, 1978) e Brasil (Amazonas, Pará e Bahia), no domínio da floresta amazônica, especialmente sobre latossolos, e em áreas de Cerrado (Bahia). É provável que um maior esforço de coleta no Tocantins, Maranhão e Piauí evidencie a presença desta espécie nestes estados. Floresce e frutifica entre os meses de setembro e outubro.

É bastante peculiar entre as espécies do gênero e distingui-se das demais co-genéricas pela presença de numerosas glândulas discóides na superfície abaxial do limbo foliar, pontuações negras presentes na superfície adaxial, lacínios do cálice de margem sinuada e corola alvo-rósea. Amasonia spruceana é popularmente conhecida como "rabo de zorro" (Moldenke 1982).

\section{Agradecimentos}

Ao Conselho Nacional de Desenvolvimento e Pesquisa (CNPq) a concessão da bolsa de mestrado, ao Programa de Pós-Graduação em Botânica (PPGB) da Universidade Federal Rural de Pernambuco e aos curadores dos herbários o empréstimo de exsicatas. A Franck Silva o auxílio com as ilustrações.

\section{Referências}

Abu-Asab, M.S. \& Cantino, P.D. 1992. Pollen morphology in subfamily Lamioideae: phylogenetics implicatons. In: Harley, R.M. \& Reynolds, T. (eds.).
Advances in Labiate science. Royal Botanic Gardens, Kew. Pp. 97-112.

Aublet, M.F. 1775. Histoire des plantes de la Guiane Françoise II. 596p.

Bentham, G. 1839. Annals of Natural History 2. 451p.

Bentham, G. 1876. Verbenaceae In: Bentham, G.; Hooker, J.D. (eds.). Genera Plantarum. Vol.2. London. Pp.1132-1136.

Briquet, I. 1895. Verbenaceae. In: Engler \& Prantl (eds.). Die Natürlich Pflanzenfamilien $48^{\text {nd }}, 17 \mathrm{p}$.

Briquet, I. 1935. International rules of botanical nomenclature. International Botanical Congress, Cambridge, 1930. Verlag von Gustav Ficher, Jena.

Brummitt, R.F.; Powell, C.E. 1992. Authors of plant names. Royal Botanic Gardens, Kew. 732p.

Cantino, P.D. 1992 a. Evidence for a polyphyletic origin of the Lamiaceae. Annals of the Missouri Botanical Garden 79: 361-379.

Cantino, P.D. 1992 b. Toward a phylogenetic classification of the Lamiaceae. In: Harley, R.M. \& Reynolds, T. (eds.). Advances in Labiate science. Royal Botanic Gardens, Kew. Pp. 27-37.

Cantino, P.D.; Harley, R.M. \& Wagstaff, S.J. 1992. Genera of Lamiaceae: status and classification. In: Harley, R.M. \& Reynolds, T. (eds.). Advances in Labiate science. Royal Botanic Gardens, Kew. Pp. 511-522.

Harley, R.M.; Atkins, S.; Budantsev, A.L.; Cantino, P.D.; Conn, B.J.; Grayer, R.; Harley, M.M.; De Kok, R.; Krestovskaja, T.; Morales, R.; Paton, A.J.; Ryding, O.; Upson, T. 2004. Lamiaceae. In: Kubitzki, K.; Kadereit, J.W. (eds.). The families and genera of vascular plants. Vol. 7. Springer Verlag, Berlin. Pp. 167-275.

Harris, J.G.; Harris, M.W. 2001. Plant identification terminology. An illustrated glossary. $2^{\text {nd }}$ ed. Spring Lake. 216 p.

Holmgren, P.K.; Holmgren, N.H. \& Barnett, L.C. 1990. Index Herbariorum. Part 1. The herbaria of the world. $8^{\text {th }}$ ed. The New York Botanical Garden, New York. 693 p.

Hooker, J.D. 1887. Botanical Magazine. Pp. 113, tab. 6915.

Judd, W.S.; Campbell, C.S.; Kellogg, E. A.; Stevens, P. F. \& Donoghue, M.J. 2009. Sistemática vegetal: um enfoque filogenético. $3^{\mathrm{a}}$. Artmed, $632 \mathrm{p}$.

Junell, S. 1934. Zur Gynäceummorphologie und Systematik der Verbenaceen und Labiaten Symbolae Botanicae Upsalienses 4: 213-214.

Lawrence, G.H.M. 1973. Taxonomia das plantas vasculares. Vol. 2. Fundação Calouste Gulbenkian, Lisboa. 256p.

Linnaeus, C. 1782. Supplementum Plantarum 48: 294.

Moldenke, H.N. 1939. A monograph of the genus Amasonia L. Repertorium Specierum Novarum Regni Vegetabilis 46: 193-228. 
Moldenke, H.N. 1946. Notes on the genus Amasonia I. In: Gleasson, H.A. \& Moldenke, H.N. (eds.). Phytologia 2: 198-200.

Moldenke, H.N. 1947. Notes on the genus Amasonia II. In: Gleasson, H.A. \& Moldenke, H.N. (eds.). Phytologia 2: 246-247.

Moldenke, H.N. 1948. Notes on the genus Amasonia III. In: Gleasson, H.A. \& Moldenke, H.N. (eds.). Phytologia 2: 502.

Moldenke, H.N. 1953. Notes on the genus Amasonia IV. In: Gleasson, H.A. \& Moldenke, H.N. (eds.). Phytologia 4: 452-456.

Moldenke, H.N. 1961. Notes on the genus Amasonia V. In: Gleasson, H.A. \& Moldenke, H.N. (eds.). Phytologia 7: 338-342.

Moldenke, H.N. 1974. Notes on the genus Amasonia VI. In: Gleasson, H.A. \& Moldenke, H.N. (eds.). Phytologia 29: 21-37.

Moldenke, H.N. 1978. Notes on the genus Amasonia VII. In: Gleasson, H.A. \& Moldenke, H.N. (eds.). Phytologia 40: 403-406.

Moldenke, H.N. 1980. Notes on the genus Amasonia VIII. In: Gleasson, H.A. \& Moldenke, H.N. (eds.). Phytologia 47: 137-140.

Moldenke, H.N. 1981a. Notes on new and noteworthy plants CXLVI. Phytologia 48: 290.

Moldenke, H.N. 1981b. Notes on new and noteworthy plants CXLVII Phytologia 48: 438.

Moldenke, H.N. 1982. Notes on the genus Amasonia IX. In: Gleasson, H.A. \& Moldenke, H.N. (eds.). Phytologia 52: 232-237.
Radford, A.E.; Dickison, W.C. \& Massey, J.R. 1974. Vascular plant systematics. Harper \& Row, New York. 891p.

Raj, B. 1983. A contribution to the pollen morphology of Verbenaceae. Review of Paleobotany and Palynology. 39: 343-422.

Rua, G.H. 1999. Inflorescencias: bases teóricas para su análisis. Sociedad Argentina de Botánica, Buenos Aires. 100p.

Schauer, J.C. 1847. Verbenaceae. In: A. P. De Candolle (ed.). Prodromus Systematis Naturalis Regni Vegetabilis. Paris \& Leipzig. 11: 522-700.

Schauer, J.C. 1867. Verbenaceae. In: Martius, C.F.P. Von \& Eichler, A.G. (eds). Flora brasiliensis. Typographia Regia. Munchen, Wien, Leipzig. Vol. 9: 166-307.

Stafleu, F.; Cowan, R.S. 1976. Taxonomic literature. Bohn, Schetelma \& Holkema, Utrecht. 991p.

Steane, D.A.; De Kok, R.P.J \& Olmstead, R.G. 2004. Phylogenetic relationships between Clerodendrum (Lamiaceae) and other ajugoid genera inferred from nuclear and chloroplast DNA sequence data. Molecular Phylogenetics and Evolution 32: 39-45.

Troncoso, N.S. 1974. Los géneros de Verbenáceas de sudamérica extratropical (Argentina, Chile, Bolívia, Paraguay, Uruguay Y sur de Brasil). Darwiniana 18: 295-407.

Wagstaff, S.J., Hickerson, L., Sprangler, R., Reeves, P.A. \& Olmstead, R.G. 1998. Phylogeny in Lamiaceae s. 1., inferred from CpDNA sequences. Plant Systematics and Evolution 209: 265-274. 